\title{
Lung Function in Newborn Infants with Tachypnea of Unknown Cause
}

\author{
KENNETH SANDBERG, BENGT-ARNE SJÖQVIST, OLA HJALMARSON, AND TORSTEN OLSSON \\ Department of Pediatrics I, Gothenburg University and Research Laboratory of Medical Electronics, Chalmers \\ University of Technology, Göteborg, Sweden
}

\begin{abstract}
Twenty-one infants with tachypnea (f $>60 /$ min) lasting more than $2 \mathrm{~h}$ and diagnosed as mild respiratory disease or pulmonary maladaptation according to previously presented criteria were studied during the course of the disease and after clinical recovery. Lung physiology (total and alveolar ventilation, efficiency and distribution of ventilation, functional residual capacity, and lung mechanics) was studied in combination with clinical data. The pathophysiological findings were characterized by increased total ventilation but normal alveolar ventilation, reduced efficiency of ventilation but more even distribution of ventilation (nitrogen elimination pattern) during disease than after clinical recovery, hyperinflation, reduced dynamic lung compliance but unaffected specific lung conductance. Infants with low gestational ages were most severely affected and had longer duration of disease than full-term infants. Our findings suggest that this condition is caused by small airway disease. Disturbances in normal pulmonary adaptation with abnormal retention of lung fluid is the most probable cause. (Pediatr Res 22: 581-586, 1987)
\end{abstract}

\section{Abbreviations}

$C_{\text {dyn }}$, dynamic lung compliance

EBF, effective breath fraction

f, respiratory frequency/min

FRC, functional residual capacity

$G_{1}$, lung conductance

IRDS, infantile respiratory distress syndrome

NC, lung nitrogen clearance

PMA, pulmonary maladaptation

$\mathbf{R}_{\mathbf{l}}$, lung resistance

$\dot{\mathbf{V}}_{\mathrm{A}}$, alveolar ventilation/min

$V_{D}$, dead space volume

$\dot{\mathbf{V}}_{\mathbf{E}}$, ventilation/min

$V_{N_{2}}$, lung nitrogen volume

$V_{T}$, tidal volume

Respiratory disturbance is a primary problem in neonatal medicine. Tachypnea with or without cyanosis or grunting soon after birth is often a presenting symptom. In a Swedish population the incidence rate of neonatal respiratory disease (respiratory frequency $>60 / \mathrm{min}$, cyanosis in room air, retractions or grunting lasting more than $2 \mathrm{~h}$ ) starting during the first 2 days of life was $2.9 \%(1)$. When "known causes" such as IRDS or hyaline mem-

Received January 16, 1987; accepted June 30, 1987.

Correspondence and reprint requests Kenneth Sandberg, M.D., Department of Pediatrics I, East Hospital, S-416 85 Göteborg, Sweden.

Supported by the Swedish Medical Research Council, Project 05703 and The Medical Faculty, Gothenburg University. brane disease, infections, meconium aspiration, pneumothorax, malformations, and cardiac disease had been carefully excluded, the majority $(2 \%)$ of causes remained unknown. These infants have been referred to variously as RDS type II (2), wet lung (3), transient tachypnea (4), and other designations. There are no clear distinction between these different respiratory disorders. Accordingly, in our present Swedish terminology all these entities are referred to as PMA (1). A delayed resorption of lung fluid postpartum has been proposed as a common etiological factor.

Despite the common occurrence little is known about the pathophysiology of this condition. In this study we wanted to assess lung function in terms of ventilation, efficiency, and distribution of ventilation (nitrogen elimination pattern), FRC, and mechanics of breathing in a group of newborn infants with tachypnea of unknown cause, and to relate the findings to the severity of the disease.

\section{METHODS}

Our methods have been described in detail elsewhere $(5,6)$. Briefly, the infant was placed in a volume displacement body plethysmograph with its face outside the box. A pneumotachograph (Fleisch 1) was mounted in the wall of the plethysmograph. The flow signal was electronically integrated to volume. After the infant had adapted to the body box $f, V_{T}$, and $\dot{V}_{E}$ were measured.

After this a face mask (dead space $2 \mathrm{ml}$ ) was placed gently over the infant's mouth and nose. A system of tubing and a nitrogen analyzer (Hewlett Packard model 47302A) were attached to the mask. During an expiration the infant's breathing air was instantaneously shifted into $100 \%$ oxygen and the nitrogen wash-out was continued until end tidal nitrogen concentration remained below $2 \%$. The nitrogen and ventilatory flow signals were recorded on a polygraph (Mingograph 81) and sampled by a minicomputer for further calculations.

FRC was calculated by dividing the expired $V_{\mathrm{N}_{2}}$ by the end tidal $\mathrm{N}_{2}$ concentration prior to the oxygen breathing. The $\mathrm{V}_{\mathrm{N}_{2}}$ was achieved by accumulating the integrated product of expired ventilatory flow and $\mathrm{N}_{2}$ concentration during oxygen breathing until $2 \%$ end tidal $\mathrm{N}_{2}$ concentration was reached. No correction was made for dissolved tissue nitrogen.

For the analysis of effective $\mathrm{V}_{\mathrm{D}}, \mathrm{V}_{\mathrm{A}}$, and nitrogen elimination pattern a linear total lung nitrogen volume elimination curve was constructed with the breath numbers on the horizontal axis. In order to determine the elimination pattern, one exponential curve or the sum of two or three were fitted to the original elimination curve by using least square minimization. The statistically most significant number of exponentials was chosen as the best estimate of the original data (6). However, if the estimate deviated significantly from the original data the exponential model was considered insufficient.

The $V_{D}$ was calculated from the dilution factor $[\mathrm{W}=\mathrm{FRC} /$ $\left.\left(F R C+V_{\Upsilon}-V_{D}\right)\right]$ achieved from the best single exponential 
estimate, and $\dot{V}_{A}$ was calculated as $f\left(V_{T}-V_{D}\right)$. EBF was calculated as $\left(\mathrm{V}_{\mathrm{T}}-\mathrm{V}_{\mathrm{D}}\right) /\left(\mathrm{V}_{\mathrm{T}}-2\right)$, where equipment dead space $(2 \mathrm{ml})$ was excluded, and the total ventilatory efficiency as $\mathrm{NC}$, defined as $n V_{T} / V_{N_{2}}$, where $n$ is the number of breaths used during the nitrogen wash-out to reach an end tidal $\mathrm{N}_{2}$ concentration of $2 \%$.

After this the baby was placed in its bed or incubator in a supine position for measurement of the mechanics of breathing. This was done by means of an esophageal balloon placed through the infant's left nostril in the lower part of the esophagus and a pneumotachograph attached to a face mask. The system for measurement of esophageal pressure has been described previously by means of an airway occlusion technique in full-term infants (8). $V_{T}$ was obtained by electric integration of the flow signal. The measurement equipment was tested and found not to deviate in phase and amplitude up to $10 \mathrm{~Hz}$. The ventilatory flow, volume, and pressure signals were recorded on a polygraph (Minograph 81). $C_{d y n}$ was calculated at moments of zero flow and $R_{I}$ at midvolume. The measurements were made during quiet sleep and regular breathing, without signs of rapid eye movements or chest wall distorsion. The results were given as the average of at least five breaths. Specific lung compliance was calculated as $\mathrm{C}_{\mathrm{dyn}} / \mathrm{FRC}$. Specific conductance was calculated as $\mathrm{G}_{1} /$ FRC, where $\mathrm{G}_{1}=\mathrm{l} / \mathrm{R}_{\mathrm{l}}$.

In the statistical analysis Student's paired $t$ test, Fishèr's exact test, and analysis of variance and covariance were used. The data are presented as mean \pm SEM if not otherwise indicated. In the infants where repeated examinations were made during the disease, the first observation in the tables represents the diseased state.

\section{MATERIAL}

Twenty-one newborn infants with respiratory disease, manifested by one or more of the following signs: breathing frequency $>60 / \mathrm{min}$, cyanosis in room air, retractions or grunting which had started soon after birth and lasted for more than $2 \mathrm{~h}$, were examined repeatedly during the course of the disease and after clinical recovery. Infections were carefully excluded in all infants by means of blood cultures, repeated examinations of $C$ reactive protein, and total and differential blood counts. Infants with clinical signs of IRDS or hyaline membrane disease, according to previously presented criteria (1), were excluded from the study. Neither showed any infant signs of meconium aspiration, pneumothorax, malformations or cardiac disease according to clinical examination. The studied infants all had a mild to moderately severe respiratory disease with continuous improvement during the first days of life. The median birth weight was $3.14 \mathrm{~kg}$ (range 1.85 to $4.30 \mathrm{~kg}$ ). The median gestational age was $37 \mathrm{wk}$ (range 33 to $41 \mathrm{wk}$ ). Ten infants had been delivered by cesarean section. Five infants had Apgar scores $\leq 6$ at $1 \mathrm{~min}$ and two infants had diabetic mothers. In order to investigate possible connections between data on lung function and the severity of the disease, each infant was referred to one of three groups. Group I comprised infants with clinical signs of respiratory disease but with normal lung $x$-ray. Group II included all infants with pathological chest $x$-ray and calculated right to left shunt of less than $40 \%$ at $6 \mathrm{~h}$ of age. The shunt was calculated according to a nomogram using actual $\mathrm{F}_{\mathrm{i}} \mathrm{O}_{2}$ and arterial or transcutaneous $\mathrm{pO}_{2}$ (1). Group III included all infants with pathological chest $x$-ray and calculated shunt of $\geq 40 \%$ at $6 \mathrm{~h}$ of age.

The pathological chest $x$-ray included reduced translucency, infiltrates, pleural liquid, or hyperinflation. No infant had a reticulogranular pattern. Five infants were referred to group I, 11 to group II, and five to group III. The first examination of lung function was made $1-28 \mathrm{~h}$ after birth (median $6 \mathrm{~h}$ ) and the last after clinical recovery (respiratory frequency $<60 / \mathrm{min}$ during air breathing) at $24-144 \mathrm{~h}$ of age (median $79 \mathrm{~h}$ ).

Blood gases were followed via an umbilical artery catheter or via transcutaneous oxygen monitoring. All infants breathed spontaneously and none showed signs of respiratory insufficiency requiring mechanical ventilation during the course of the disease.

Before the examination parental consent was obtained for all infants and the study was approved by the ethical committee of the university.

\section{RESULTS}

Clinical data for the separate groups of infants are presented in Table 1. There were significant differnces between the groups in birth weight, gestational age, duration of tachypnea, and oxygen therapy. The infants in group III had the lowest birth weights and lowest gestational ages. The infants in group I had the highest birth weight and were full term. For all infants studied there was a significant positive correlation between calculated right to left shunt at $6 \mathrm{~h}$ of age and the duration of tachypnea $(r$ $=0.82, p<0.001$ ).

The ventilatory parameters during the disease and after clinical recovery are presented in Table 2 . During the nitrogen wash-out test ventilation was higher than when the infant was resting in the plethysmograph without the face mask. This difference was statistically significant $(p<0.02)$ in all infants only during the disease. The increased ventilation could only partly be explained by the added dead space. The remainder is regarded as a direct effect on ventilation of the application of the mask system to the face of the infant.

During the disease the whole group showed significantly higher respiratory frequency, total ventilation, and lower $V_{T}$, as compared to after clinical recovery. Alveolar ventilation was unaffected. There was a significant correlation between $V_{T}$ and $V_{D}$ both during disease and after clinical recovery $(p<0.01)$. Dead space was significantly increased in the total group during disease after variance due to differences in $V_{\mathrm{T}}$ between the examinations was compensated for by covariance analysis (adjusted means 6.2 versus $4.9 \mathrm{ml}, p<0.01$ ). The same pattern of change in ventilation was also found when all infants were divided into the separate groups I, II, and III. However, the magnitude in the differences in parameters between health and disease differed among the groups. Group III showed the greatest change in ventilation and group I was least affected by the disease.

Table 1. Clinical data for groups studied

\begin{tabular}{|c|c|c|c|c|}
\hline Group & I & II & III & $\begin{array}{c}\text { Analysis } \\
\text { of } \\
\text { variance }\end{array}$ \\
\hline$n$ & 5 & 11 & 5 & \\
\hline Birth wt $(\mathrm{kg})$ & $3.51 \pm 0.19$ & $3.17 \pm 0.05$ & $2.65 \pm 0.10$ & $p<0.05$ \\
\hline $\begin{array}{l}\text { Gestational age } \\
\text { (wk) }\end{array}$ & $39 \pm 0.3$ & $37 \pm 0.7$ & $35 \pm 0.6$ & $p<0.05$ \\
\hline $\begin{array}{l}\text { Duration of } \\
\text { tachypnea (f } \\
\left.>60 \mathrm{~min}^{-1}\right) \\
\text { (days) }\end{array}$ & $0.8 \pm 0.1$ & $2.3 \pm 0.6$ & $5.0 \pm 0.3$ & $p<0.01$ \\
\hline $\begin{array}{l}\text { Duration of oxy- } \\
\text { gen therapy } \\
\text { (days) }\end{array}$ & $0.1 \pm 0.1$ & $1.2 \pm 0.3$ & $5.4 \pm 0.3$ & $p<0.001$ \\
\hline $\begin{array}{l}\text { Maximum right } \\
\text { to left shunt } \\
\text { after } 6 \mathrm{~h} \text { of } \\
\text { age }(\%)\end{array}$ & $4 \pm 4$ & $18 \pm 5$ & $50 \pm 4$ & $p<0.01$ \\
\hline $\begin{array}{c}\text { Apgar score } \leq 6 \\
\text { at } 1 \mathrm{~min}\end{array}$ & $2 / 5$ & $2 / 11$ & $1 / 5$ & \\
\hline Cesarean section & $4 / 5$ & $4 / 11$ & $2 / 5$ & \\
\hline Diabetic mother & 0 & $2 / 11$ & 0 & \\
\hline $\begin{array}{l}\text { Age at examina- } \\
\text { tion* }(\mathrm{h})\end{array}$ & & & & \\
\hline Disease & $4(1-14)$ & $6(3-25)$ & $11(6-28)$ & \\
\hline Recovery & $25(24-39)$ & $79(27-132)$ & $127(99-144)$ & \\
\hline
\end{tabular}

* Median (range). 
LUNG FUNCTION IN TACHYPNOIC NEWBORNS

Table 2. Ventilatory parameters

\begin{tabular}{|c|c|c|c|c|c|c|c|c|}
\hline & \multicolumn{3}{|c|}{ Before nitrogen wash-out } & \multicolumn{5}{|c|}{ During nitrogen wash-out* } \\
\hline & $\begin{array}{c}f \\
\left(\min ^{-1}\right)\end{array}$ & $\begin{array}{c}V_{r} \\
(\mathrm{ml})\end{array}$ & 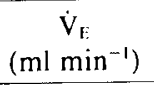 & $\begin{array}{c}f \\
\left(\min ^{-1}\right)\end{array}$ & $\begin{array}{l}V_{\mathrm{T}} \\
(\mathrm{ml}) \\
\end{array}$ & $\begin{array}{l}\mathrm{V}_{\mathrm{D}} \\
(\mathrm{ml})\end{array}$ & $\begin{array}{c}\dot{\mathrm{V}}_{\mathrm{E}} \\
\left(\mathrm{ml} \mathrm{min} \mathrm{min}^{-1}\right)\end{array}$ & $\begin{array}{c}\dot{\mathrm{V}}_{\mathrm{A}} \\
\left(\mathrm{ml} \mathrm{min}{ }^{-1}\right)\end{array}$ \\
\hline All infants & & & & & & & & \\
\hline Disease & $80 \pm 4.5$ & $9.1 \pm 0.4$ & $720 \pm 42$ & $85 \pm 5.6$ & $11 \pm 0.8$ & $5.9 \pm 0.5$ & $860 \pm 68$ & $372 \pm 32$ \\
\hline Recovery & $49 \pm 1.9$ & $12 \pm 0.6$ & $563 \pm 34$ & $59 \pm 2.7$ & $12 \pm 1.0$ & $5.2 \pm 0.7$ & $661 \pm 63$ & $363 \pm 33$ \\
\hline Difference & $30 \pm 5.2 \dagger$ & $-2.4 \pm 0.5 \dagger$ & $157 \pm 49 \ddagger$ & $27 \pm 5.6 \dagger$ & $-1.2 \pm 0.6$ & $0.7 \pm 0.6 \S$ & $199 \pm 63 \ddagger$ & $8 \pm 63$ \\
\hline \multicolumn{7}{|l|}{ Group I } & & \\
\hline Disease & $70 \pm 4.0$ & $11 \pm 0.4$ & $732 \pm 44$ & $75 \pm 9.8$ & $13 \pm 1.0$ & $6.8 \pm 0.8$ & $970 \pm 169$ & $\begin{array}{l}449 \pm 10 \\
516+87\end{array}$ \\
\hline Recovery & $51 \pm 3.9$ & $14 \pm 1.6$ & $698 \pm 73$ & $62 \pm 6.6$ & $16 \pm 2.3$ & $6.9 \pm 1.0$ & $940 \pm 145$ & $\begin{array}{l}516 \pm 87 \\
-67+75\end{array}$ \\
\hline Difference & $19 \pm 1.9 \dagger$ & $-3.3 \pm 1.2$ & $33 \pm 40$ & $13 \pm 10$ & $-2.7 \pm 1.7$ & $-0.1 \pm 1.0$ & $30 \pm 151$ & $-67 \pm 75$ \\
\hline \multicolumn{9}{|l|}{ Group II } \\
\hline Disease & $82 \pm 6.1$ & $9.0 \pm 0.5$ & $746 \pm 70$ & $84 \pm 6.2$ & $11 \pm 1.1$ & $6.0 \pm 0.7$ & $\begin{array}{l}852 \pm 97 \\
650+70\end{array}$ & $\begin{array}{l}348 \pm 31 \\
344+30\end{array}$ \\
\hline Recovery & $49 \pm 2.3$ & $11 \pm 0.6$ & $555 \pm 40$ & $58 \pm 4.1$ & $12 \pm 1.3$ & $5.6 \pm 1.0$ & $\begin{array}{l}650 \pm 70 \\
202+79 \|\end{array}$ & $\begin{aligned} 344 \pm 30 \\
4 \pm 43\end{aligned}$ \\
\hline Difference & $34 \pm 8 \ddagger$ & $-2.4 \pm 0.7 \ddagger$ & $191 \pm 79 \|$ & $26 \pm 5.7 \ddagger$ & $-1.2 \pm 0.8$ & $0.4 \pm 0.7$ & $202 \pm 79 \|$ & $4 \pm 43$ \\
\hline \multicolumn{8}{|l|}{ Group III } & \\
\hline Disease & $84 \pm 13$ & $8.0 \pm 0.6$ & $654 \pm 77$ & $99 \pm 17$ & $8.3 \pm 1.2$ & $4.5 \pm 0.8$ & $\begin{array}{l}768 \pm 104 \\
406+23\end{array}$ & $\begin{array}{l}345 \pm 28 \\
252+44\end{array}$ \\
\hline $\begin{array}{l}\text { Recovery } \\
\text { Difference }\end{array}$ & $49 \pm 5.3$ & $\begin{array}{r}9.4 \pm 0.9 \\
-14+10\end{array}$ & $446 \pm 45$ & $\begin{array}{l}53 \pm 3.6 \\
46 \pm 15 \|\end{array}$ & $\begin{array}{l}7.7 \pm 0.3 \\
0.6 \pm 1.1\end{array}$ & $\begin{array}{l}2.6 \pm 1.1 \\
1.9 \pm 1.7\end{array}$ & $\begin{array}{l}406 \pm 23 \\
363 \pm 110 \|\end{array}$ & $\begin{array}{r}252 \pm 44 \\
93 \pm 45\end{array}$ \\
\hline
\end{tabular}

* Equipment dead space excluded.

$\dagger p<0.001$.

$\ddagger p<0.01$.

$\S$ Difference significant $(p<0.01)$ when variance due to differences in corresponding $\mathrm{V}_{\mathrm{T}}$ between the examinations was compensated for by means of covariance analysis.

$\| p<0.05$.

FRC was significantly larger during disease in infants with pathological chest $x$-ray when compared to after recovery $(p<$ 0.05 for group II + III, Table 3). Although not statistically significant, hyperinflation of the lung during disease was more pronounced in group III than in group II. However, the individual variations were considerable (Fig. 1). In group I FRC was the same during and after the disease period.

Efficiency of ventilation measured as effective breath fraction and nitrogen clearance is presented in Table 3 . There was a significant reduction in efficiency of ventilation during disease. EBF for all infants was $0.44 \pm 0.02$ during disease and $0.58 \pm$ 0.05 after clinical recovery $(p<0.01)$. The corresponding values for $\mathrm{NC}$ in the whole group were $15.6 \pm 0.8$ and $12.9 \pm 0.6(p<$ 0.01 ). Although not statistically significant the reduction in efficiency of ventilation during disease was most pronounced in group III infants and was least pronounced in group I infants. The nitrogen elimination pattern analysis showed single rather than multiple exponential wash-out curves significantly more frequently during disease than after clinical recovery $(p=0.03$ Fisher's exact test). At the first examination single exponential wash-out pattern was found in 14 cases and two exponential wash-out pattern in four, while our lung model could not satisfactory describe the wash-out course in three cases. After recovery the corresponding values were 7,7 , and 7 respectively.

The lung mechanical parameters are presented in Table 4. There was a significant reduction in $\mathrm{C}_{\mathrm{dyn}}$ during disease compared with after recovery $\left(1.9 \pm 0.2\right.$ versus $3.4 \pm 0.2 \mathrm{ml} / \mathrm{cm} \mathrm{H}_{2} \mathrm{O}$ for the whole group, $p<0.001)$. Specific $C_{\mathrm{dyn}}$ showed the same change $(p<0.001)$. There was a significant difference in $\mathrm{C}_{\mathrm{dyn}}$ between the different groups during disease $(p<0.05)$ with the lowest $C_{d y n}$ in group III infants. There was a continuous improvement in $\mathrm{C}_{\mathrm{dyn}}$ during the disease in most infants (Fig. 1). However, a tendency to deterioration in $C_{d y n}$ during the 2 nd day of life could be observed in the infants belonging to group III. $R_{1}$ was significantly higher after clinical recovery than during the disease $(p<0.05)$. However, specific conductance showed no significant change.
Table 3. Efficiency of ventilation and lung volume

\begin{tabular}{lccc} 
& EBF & NC & FRC $(\mathrm{ml})$ \\
\hline All infants & & & \\
Disease & $0.44 \pm 0.02$ & $15.6 \pm 0.8$ & $70 \pm 5.0$ \\
Recovery & $0.58 \pm 0.05$ & $12.9 \pm 0.6$ & $61 \pm 3.6$ \\
Difference & $-0.14 \pm 0.04^{*}$ & $2.7 \pm 0.8^{*}$ & $9.3 \pm 4.9$ \\
& & & \\
Group I & & & \\
Disease & $0.47 \pm 0.03$ & $13.0 \pm 0.5$ & $73 \pm 9.0$ \\
Recovery & $0.55 \pm 0.03$ & $11.2 \pm 0.8$ & $75 \pm 7.2$ \\
Difference & $-0.08 \pm 0.03$ & $1.8 \pm 0.6 \dagger$ & $-2.7 \pm 4.3$ \\
& & & \\
Group II & & & \\
Disease & $0.41 \pm 0.04$ & $15.6 \pm 1.1$ & $68 \pm 7.2$ \\
Recovery & $0.57 \pm 0.07$ & $13.0 \pm 0.4$ & $61 \pm 3.9$ \\
Difference & $-0.16 \pm 0.05^{*}$ & $2.6 \pm 1.0 \dagger$ & $7.0 \pm 6.1$ \\
& & & \\
Group III & & & \\
Disease & $0.46 \pm 0.04$ & $18.2 \pm 1.4$ & $71 \pm 13$ \\
Recovery & $0.64 \pm 0.14$ & $14.5 \pm 2.0$ & $44 \pm 4.8$ \\
Difference & $-0.18 \pm 0.14$ & $3.7 \pm 2.7$ & $26 \pm 13$ \\
\hline
\end{tabular}

$* p<0.01$.

$+p<0.05$.

\section{DISCUSSION}

The infants in this study have a condition previously variously called RDS type II (2), wet lung (3), transient tachypnea (4), and other designations. However, there are no clear distinctions between these disorders. It has been proposed that the cause of the condition is a disturbance in normal pulmonary postnatal adaptation with delay in resorption of lung fluid after delivery, resulting in lung edema. The common occurrence after cesarean section supports this view (9). In this study 10 of the 21 infants examined were delivered by cesarean section. Disturbances in circulatory adaptation after delivery, including pulmonary arte- 


\section{Group I}

Groud II

\section{Group III}
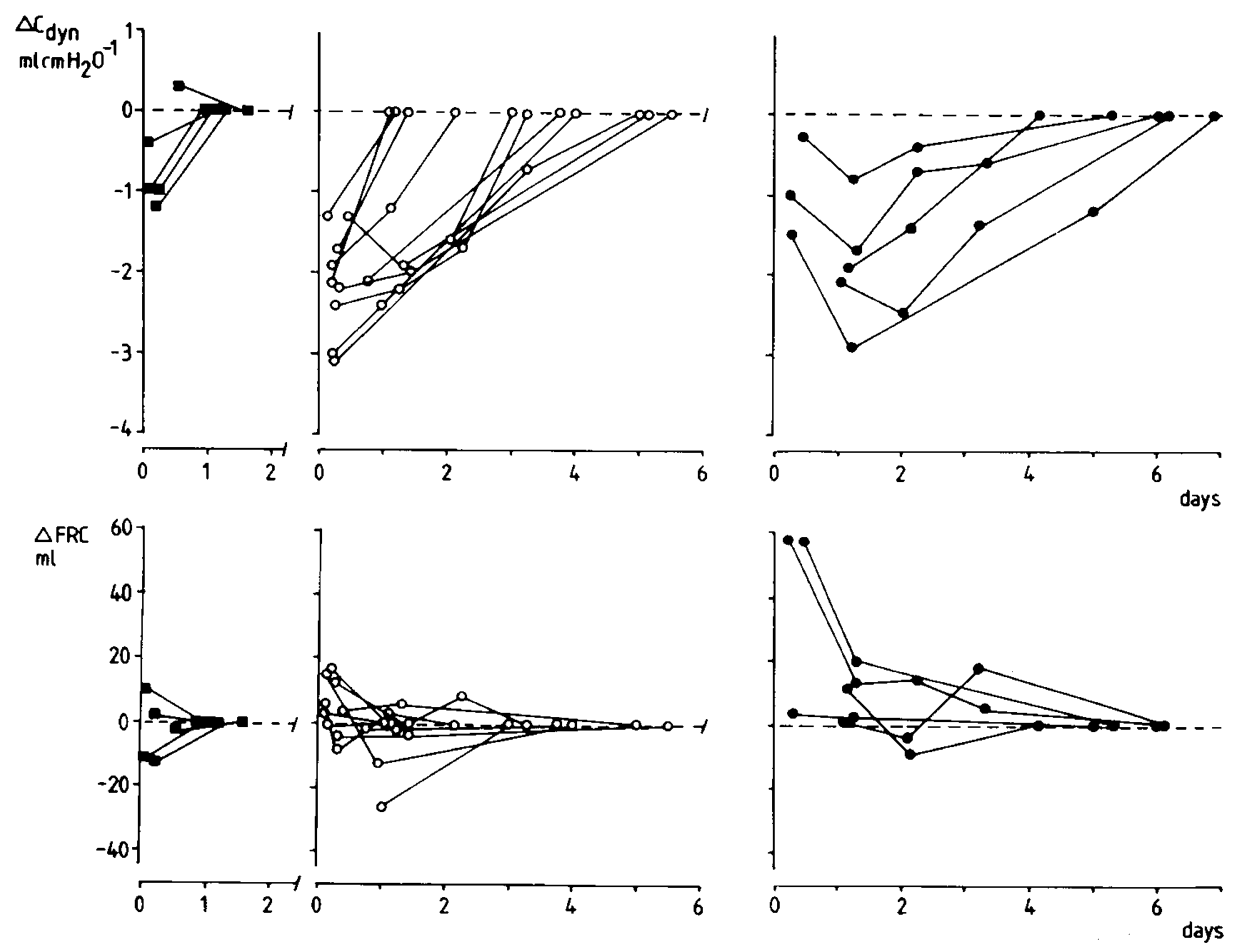

Fig. 1. The difference in measurements during disease and after recovery in dynamic lung compliance $\left(\Delta \mathrm{C}_{\mathrm{dyn}}\right)$ and functional residual capacity $(\triangle \mathrm{FRC})$. The zero values represent the last studies which are included in the text as the recovery values.

Table 4. Mechanics of breathing

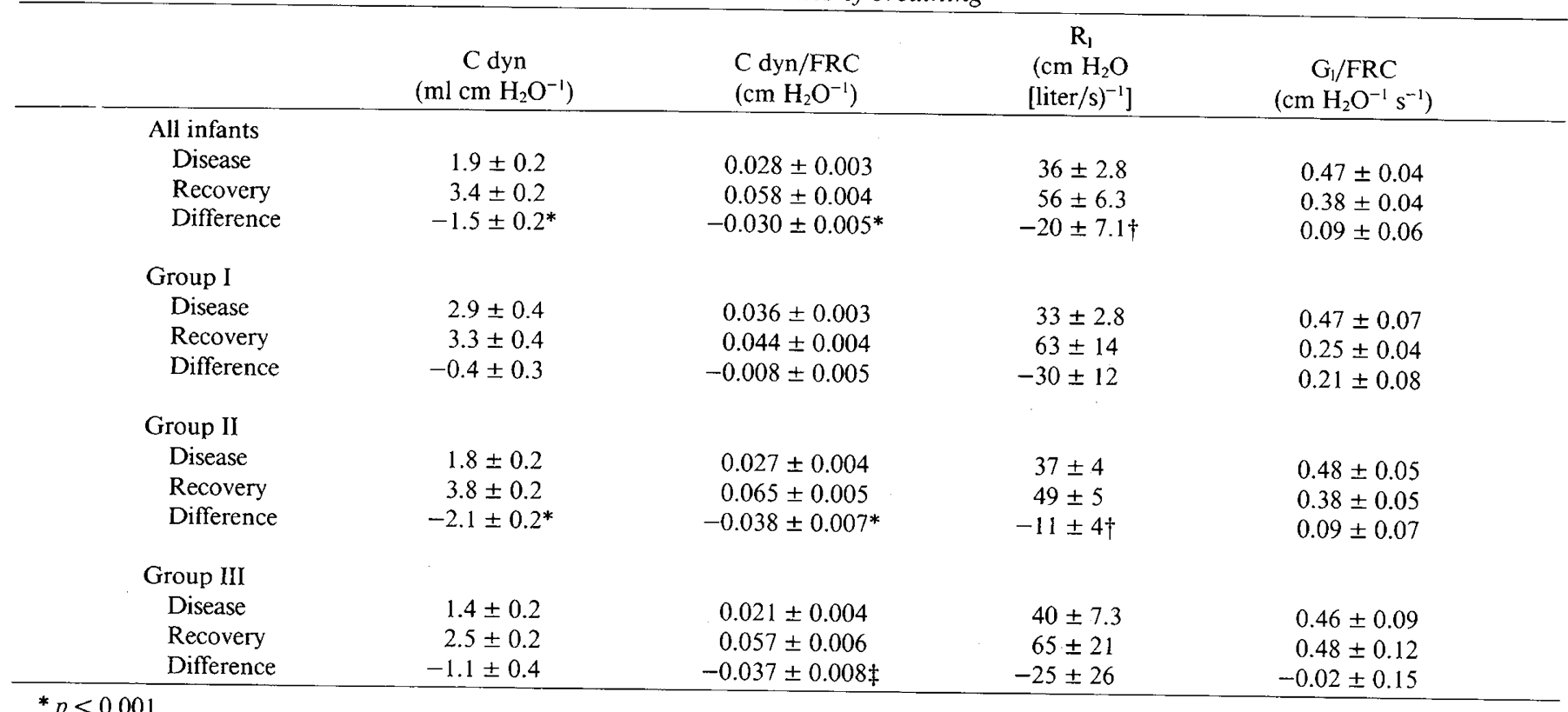

$$
\dagger p<0.05 \text {. }
$$$$
\ddagger p<0.01 \text {. }
$$

rial hypertension and inefficient left and right ventricular performance have also been proposed as causes (10).

The course and severity of the disease varied among the infants in our study (Table 1). The infants with the lowest birth weights and lowest gestational ages had the most severe clinical courses. In agreement with what has been reported by Prod'hom et al. (2) we found different patterns of recovery. In some cases the calculated right to left shunt decreased markedly as early as over the first $6 \mathrm{~h}$ of life. In other infants improvement was slower. The calculated shunt at $6 \mathrm{~h}$ of age correlated well with the duration of the disease.

The methods used for the examination of lung function enabled us to study essential parameters with minimal effects on the sick infant. The nitrogen wash-out data were analyzed by a computer based method through which the considerable errors accompanying manual curve-fitting were avoided. The direct 
measurement, in newborn infants, of pleural pressure change during breathing has recently been controversial. Healthy newborn infants, with birth weight less than $1500 \mathrm{~g}$ and with compliant chest walls, have been found not always to have approximately equal pressure change in the month and the esophagus in airway occlusion tests during spontaneous breathing $(11,12)$. Such a marked difference has more persistently been found in intubated newborns with respiratory disease, regardless of body weight $(13,14)$. The interpretation has been that esophageal pressure measurements do not reflect mean pleural pressure under these circumstances. On the other hand, occlusion tests on full-term, healthy, or convalescent unintubated infants have not revealed such discrepancies $(8,15)$.

Although we have tested our method on healthy, full-term, newborn infants (8) we did not perform occlusion tests to validate our measurements of esophageal pressure variations in this study. There are, however, several reasons to believe that our results are valid: 16 of the 21 infants studied had gestational ages of 36 wk or more, 18 weighed more than $2500 \mathrm{~g}$ and none was intubated. None of these essentially mature infants had irregular breathing or more than minimal chest distortion during the study. The series of $C_{d y n}$, measured during the full course of the disease in the infants, as seen in Figure 1, showed a close and consistent relation to the clinical condition. It might also be noted that if any of the pressure measurements during the acute phase of the study still was affected by bias of the kind now discussed this should have lead to an overestimation of $\mathrm{C}_{\mathrm{dyn}}$. In that case this would not have lead to any change in the observed pattern of a reduction of $C_{\text {dyn }}$ during the disease in the affected infants. Furthermore, if significant differences in regional pleural pressure existed during the disease, it is probable that the nitrogen elimination pattern should have shown a multiple exponential wash-out course instead of single exponential pattern which dominated at the first examination.

The pattern of changes in lung physiology was remarkably uniform in the total group of infants studied, although the degree of abnormality varied and correlated well with the clinical course. This implies that the infants studied herein seem to belong to a common group of infants with disturbance in the pulmonary adaptation postpartum where the maturity of the infant modifies the severity of the disease.

When compared to healthy newborn infants previously studied in our laboratory $(16,17)$, the infants in the present study, at the first examination, had high total ventilation, high breathing frequency, low $\mathrm{V}_{\mathrm{T}}$, high $\mathrm{V}_{\mathrm{D}}$, prolonged nitrogen clearance, and low $C_{\text {dyn }}$, after variations in body weight had been considered by covariance analysis. Alveolar ventilation, $\mathrm{R}_{1}$, and FRC did not differ significantly from healthy infants. After recovery no significant differences were found when the same comparisons were made.

When the data from the acute phase were compared with those after recovery in the same infants, the same pattern appeared. The only difference was that FRC was found to be significantly higher in the first compared to the last measurement in group II + III. This indicates some degree of hyperinflation during the disease in the most severely affected infants.

The ventilatory pattern with an increase in respiratory frequency along with a reduced $V_{T}$ could be regarded as an adaptation to the low lung compliance. Despite the maintained alveolar ventilation, hypoxia was a common finding, which has been proposed to be due to disturbances in ventilation perfusion ratio (18).

Uneven ventilation in the lung might be responsible for the impaired gas mixing. In this study, a single exponential washout pattern dominated during disease, and according to traditional interpretation this suggests that no detectable regional gas inhomogeneity was present in the lung. For the same reason, the low $C_{d y n}$ is not readily explained by uneven distribution of ventilation. As specific $C_{d y n}$ was also reduced during disease, increased elastic lung recoil is the most likely explanation. This might be caused by abnormal retention of lung fluid in the interstitial lung tissue after delivery. Studies in animals have shown that lung edema is preferentially located around airways and vessels in the lung interstitium (19). Such accumulation of interstitial fluid might cause compression of airways which might explain the elevated lung volumes found in the more severely affected infants. As lung conductance was unaffected, the site of such airway obstruction was probably in the small airways. As flow rate is normally low in the peripheral airways, reduction in small airway diameter would primarily affect gas mixing efficiency (20), as was observed.

The single exponential course of the nitrogen volume elimination curve was significantly less common after clinical recovery. It is well known that an increase in ventilatory flow decreases regional gas inhomogeneity or uneven distribution of the inspired gas in the lung (21). During recovery, remaining small airway disease might be unmasked by the decrease in ventilatory flow.

According to the data presented, the severity of the disease seems to be determined by the degree of small airway disease. In group I FRC did not decrease after recovery, but neither did it increase over the lst day of life as in healthy infants (16), which may indicate some peripheral airway involvement at the first measurement. In groups II and III high FRC in disease was more pronounced. Low gestational age seems to increase the disposition to peripheral airway obstruction in newborn infants with this condition. It is of interest that this pattern differs considerably from what has been found in IRDS, where lung compliance is also reduced, but together with low $\operatorname{FRC}(7,22,23)$.

From the data presented we propose that pulmonary maladaptation (and their synonyms "transient tachypnea" and "RDS type II") is a small airway disease with a pathophysiology distinct from that in IRDS.

\section{REFERENCES}

1. Hjalmarson O 1981 Epidemiology and classification of acute, neonatal respiratory disorders. Acta Paediatr Scand 70:773-783

2. Prod'hom S, Levison H, Cherry RB, Smith CA 1965 Adjustment of ventilation, intrapulmonary gas exchange, and acid-base balance during the first day of life. Infants with early respiratory disease. Pediatrics 35:662-676

3. Wesenberg RL, Grauen SN, McCabe EB 1971 Radiological findings in wetlung disease. Radiology 98:69-74

4. Avery ME, Gatewood OB, Brumley G 1966 Transient tachypnea of the newborn. Am J Dis Child 111:380-385

5. Sjöqvist BA. Sandberg K. Hjalmarson O, Olsson T 1984 Calculation of lung volume in newborn infants by means of a computer-assisted nitrogen washout method. Pediatr Res 18:1160-1164

6. Sjöqvist BA, Sandberg K, Hjalmarson O, Olsson T 1986 Method for analyzing multiple breath nitrogen washouts. Med Biol Eng Comput 24:83-90

7. Hjalmarson O 1974 Mechanics of breathing in newborn infants with pulmonary disease. Acta Paediatr Scand [Suppl] 247

8. Sandberg K 1984 Analysis of normal and abnormal ventilatory adaptation in newborn infants. Thesis, Gothenburg University, Gothenburg, Sweden

9. Krantz ME, Wennergren M, Bengtson LGW, Hjalmarson O, Karlsson K. Sellgren U 1986 Epidemiological analysis of the increased risk of disturbed neonatal respiratory adaptation after Caesarean section. Acta Paediatr Scand 75:832-839

10. Halliday HL. McClure G, Reid MMc 1981 Transient tachypnea of the newborn: two distinct clinical entities? Arch Dis Child 56:322-325

11. Le Souef PN, Lopes JM, England SJ, Bryan MH, Bryan AC 1983 Influence of chest wall distortion on esophageal pressure. J Appl Physiol 55:353-358

12. Le Souef PN, Lopes JM, England SJ, Bryan MH, Bryan AC 1983 Effect of chest wall distorsion on occlusion pressure and the preterm diaphragm. J Appl Physiol 55:359-364

13. Thomson A. Elliott J, Silverman M 1983 Pulmonary compliance in sick low birth weight infants. Arch Dis Child 58:891-896

14. Heaf DP, Turner H, Stocks J, Helms P 1983 Oesophageal pressure measurement in sick intubated infants. Biol Neonate 43:297-298(abstr)

15. Milner AD, Saunders RA, Hopkin JE 1978 Relationship of intra-oesaphageal pressure to month pressure during the measurement of thoracic gas volume in the newborn. Biol Neonate 33:314-319

16. Sandberg K, Sjöqvist BA, Hjalmarson O, Olsson T 1984 Analysis of alveolar ventilation in the newborn. Arch Dis Child 59:542-547

17. Sandberg K. Sjöqvist BA, Hjalmarson O. Olsson T 1986 Effects of delivery by caesarean section on lung function in healthy newborn infants. Acta Paediatr Scand 75:470-476

18. Sundell H, Garrot J, Blankenship WJ, Shepard FM, Stahlman MT 1971 Studies on infants with type II respiratory distress syndrome. Pediatrics 78:754-764 
19. Staub NC, Nagano H, Pearce ML 1967 Pulmonary edema in dogs, especially the sequence of fluid accumulation in lung. $J$ Appl Physiol 22:227-240

20. Engel L 1983 Gas mixing within the acinus of the lung. J Appl Physiol 54:609 618

21. Bake B, Wood L, Murphy B, Macklem PT, Milic-Emili J 1974 Effect of inspiratory flow rate on regional distribution of inspired gas. J Appl Physiol
$37: 8-17$

22. Berglund G, Karlberg P 1956 Determination of the functional residual capacity in newborn infants: preliminary report. Acta Paediatr Scand 45:541-544

23. Chu J, Clements JA, Cotton EK, Klaus MA, Sweet AY, Tooly WH 1967 Neonatal pulmonary ischemia. Part I: Clinical and physiological studies. Pediatrics 40:709-782 